J. Dairy Sci. 97:1313-1318

http://dx.doi.org/10.3168/jds.2013-7415

(C) American Dairy Science Association ${ }^{\circledR}, 2014$.

\title{
Short communication: Development of a novel method for the extraction of norbixin from whey and its subsequent quantification via high performance liquid chromatography
}

\author{
R. E. Campbell, ${ }^{*}$ I. A. L. A. Boogers, † and M. A. Drake ${ }^{\star 1}$ \\ *Department of Food, Bioprocessing and Nutrition Sciences, Southeast Dairy Foods Research Center, North Carolina State University, \\ Raleigh 27695 \\ †DSM Biotechnology Center, Analysis Department, $6401 \mathrm{JH}$ Delft, the Netherlands
}

\begin{abstract}
Norbixin is the primary carotenoid in annatto coloring, which imparts the desired orange color in Cheddar cheese. However, a portion of the colorant remains in the cheese whey and is undesirable; therefore, a bleaching step is often applied. Restrictions exist for norbixin concentrations in products destined for infant formula. As such, evaluation of norbixin concentrations in whey and whey ingredients is desirable. Current extraction methods are laborious and require solvents that are banned in many countries. The objective of this study was to develop a fast and inexpensive norbixin extraction and quantitation technique using approved solvents with similar sensitivity to current established methods. Instead of solvent extraction and column purification, acetonitrile was added directly to fluid wheys, retentates, and rehydrated whey protein concentrates. An isocratic mobile phase $[70 \%$ acetonitrile and $30 \%$ water with $0.1 \%$ (wt/vol) formic acid] was used and, to increase sensitivity, a large volume $(50 \mu \mathrm{L})$ was injected onto the column. The column used was a C18 column with a particle size of $2.6 \mu \mathrm{m}$ and column length of $10 \mathrm{~cm}$. The column inner diameter was 4.6 $\mathrm{mm}$ and the pore size was $100 \AA$ Á. All of the previously described conditions allowed the run time to be only 4 min. The sample was sent through a photodiode array detector and quantified at $482 \mathrm{~nm}$. Norbixin was quantified using external standard curves. The developed method had a $>90 \%$ norbixin recovery in both milk and whey $(9.39 \mu \mathrm{g} / \mathrm{L}-2.35 \mathrm{mg} / \mathrm{L})$. The limit of detection of norbixin in fluid whey was $2.7 \mu \mathrm{g} / \mathrm{kg}$ and the limit of quantitation was $3.5 \mu \mathrm{g} / \mathrm{kg}$, both of which are significantly lower than in previously described methods. The extracts were stable over $30 \mathrm{~min}$ at $21^{\circ} \mathrm{C}$ and stable over $24 \mathrm{~h}$ at $4^{\circ} \mathrm{C}$. Repeatability and precision of the method had relative standard deviations of less
\end{abstract}

Received August 24, 2013.

Accepted November 3, 2013.

${ }^{1}$ Corresponding author: maryanne_drake@ncsu.edu than $13 \%$. The developed method provides time and cost savings for evaluation of norbixin concentration in whey and whey products.

Key words: norbixin, annatto, whey, HPLC

\section{Short Communication}

Cheddar cheese is often colored with annatto, a yellow-orange carotenoid primarily composed of norbixin, to impart the desired orange color (Kang et al., 2010). A portion of the colorant remains in the cheese whey and is undesirable (Kang et al., 2010). To remove the color, a bleaching step is often applied. In the United States, 2 chemicals are approved for the bleaching of whey: hydrogen peroxide and benzoyl peroxide. Due to increasing regulations regarding these 2 bleaching agents, various alternative bleaching agents have been investigated (Campbell et al., 2012; Kang et al., 2012). In addition, legal limits for norbixin concentrations also exist in products destined for infant formula. As such, evaluation of norbixin concentrations in whey and whey ingredients is desirable.

High performance liquid chromatography is a highly sensitive technique used to separate and subsequently quantify nonvolatile components. Carotenoids are often measured using a photodiode array detector, which measures absorbance of eluent components at a certain wavelength. The maximum wavelength for norbixin absorbance is $482 \mathrm{~nm}$ (Kovary et al., 2001). As HPLC does not require large sample volumes, it is a very versatile technique that can be applied to a wide array of products, from food to pharmaceuticals to environmental contaminants.

Current extraction methods for norbixin are time intensive, laborious, and expensive (Lancaster and Lawrence, 1995; Scotter et al., 2002; Croissant et al., 2009; Table 1). In addition, current extraction methods require solvents that are banned in many countries. The objective of this study was to develop a fast and inexpensive extraction technique using approved solvents with similar sensitivity to current established methods. 
Table 1. Cost and time analysis of various norbixin (annatto) extraction methods (prices calculated using Fisher Scientific, Waltham, MA,as the supplier of materials)

\begin{tabular}{|c|c|c|c|}
\hline Item & Cost $(\$)$ & $\begin{array}{c}\text { Extraction time } \\
\text { (h, unless } \\
\text { otherwise noted) }\end{array}$ & $\begin{array}{c}\text { Waste } \\
(\mathrm{mL})\end{array}$ \\
\hline \multicolumn{4}{|l|}{ Scotter et al. (2002) } \\
\hline \multicolumn{4}{|l|}{ Solvent } \\
\hline $100 \mathrm{~mL}$ of hexane & 12.04 & & \\
\hline $3 \mathrm{~g}$ of celite & 0.43 & & \\
\hline $3 \mathrm{~mL}$ of $0.1 \%$ BHT (in methanol) & 0.05 & & \\
\hline $40 \mathrm{~mL}$ of ethanol:water:ammonia $(100: 35: 15)$ & 0.58 & & \\
\hline $50 \mathrm{~mL}$ of acetic acid (11\%) & 3.61 & & \\
\hline $25 \mathrm{~mL}$ of methanol & 1.34 & & \\
\hline $75 \mathrm{~mL}$ of chloroform:acetic acid $(98.5: 1.5)$ & 9.73 & & \\
\hline \multicolumn{4}{|l|}{ Disposable goods } \\
\hline Glass wool & 1.47 & & \\
\hline Total & 27.78 & 2.5 & 293 \\
\hline \multicolumn{4}{|l|}{ Lancaster and Lawrence (1995) } \\
\hline \multicolumn{4}{|l|}{ Solvent } \\
\hline $3 \mathrm{~g}$ of celite & 0.43 & & \\
\hline $75 \mathrm{~mL}$ of ethanol:water:ammonium hydroxide $(100: 35: 15)$ & 1.09 & & \\
\hline $100 \mathrm{~mL}$ of petroleum ether & 11.4 & & \\
\hline $100 \mathrm{~mL}$ of acetic acid (11\%) & 7.22 & & \\
\hline $120 \mathrm{~mL}$ of chloroform:glacial acetic acid (98.5:1.5) & 15.57 & & \\
\hline $10 \mathrm{~mL}$ of choloroform & 1.3 & & \\
\hline $55 \mathrm{~mL}$ of methanol & 3.81 & & \\
\hline \multicolumn{4}{|l|}{ Disposable goods } \\
\hline Glass wool $(\times 2)$ & 2.94 & & \\
\hline Total & 40.82 & 2.5 & 460 \\
\hline \multicolumn{4}{|l|}{ Croissant et al. (2009) } \\
\hline \multicolumn{4}{|l|}{ Solvent } \\
\hline $6 \mathrm{~mL}$ of ethanol & 0.23 & & \\
\hline $6 \mathrm{~mL}$ of chloroform & 0.78 & & \\
\hline $2 \mathrm{~mL}$ of acetic acid $(1 \%)$ & 0.07 & & \\
\hline $7 \mathrm{~mL}$ of hexane & 0.84 & & \\
\hline $5 \mathrm{~mL}$ of hexane:diethyl ether $(1: 1)$ & 0.59 & & \\
\hline $1 \mathrm{~mL}$ of acetone & 0.11 & & \\
\hline $3 \mathrm{~mL}$ of methanol:glacial acetic acid $(7: 3)$ & 0.21 & & \\
\hline \multicolumn{4}{|l|}{ Disposable goods } \\
\hline SPE Strata NH2 column ${ }^{1}$ & 4.08 & & \\
\hline Total & 6.91 & 2 & 30 \\
\hline \multicolumn{4}{|l|}{ Proposed method } \\
\hline $24 \mathrm{~mL}$ of acetonitrile:water $(80: 20)$ & 3.21 & & \\
\hline Total & 3.21 & $15 \min$ & 24 \\
\hline
\end{tabular}

${ }^{1}$ Solid-phase extraction Strata NH2 column (Phenomenex, Torrance, CA).

Linearity, stability, and repeatability were measured to confirm that the new extraction and quantification method were equivalent or better than current methods for these items.

Cheddar whey was manufactured from vat-pasteurized whole bovine milk $(195 \mathrm{~kg})$ as described by Campbell et al. (2011). To color the milk, annatto was added at a rate of $15 \mathrm{~mL} / 454 \mathrm{~kg}$ of milk (Danisco, St. Louis, MO; $3 \%$ norbixin wt/vol). The whey was drained from the curds at $\mathrm{pH} 6.35$ and a sieve was used to remove any remaining particles. The whey was immediately processed with a hot bowl cream separator (model SI600E, Agri-Lac, Miami, FL) to reduce the fat content. The whey was pasteurized at $63^{\circ} \mathrm{C}$ for $30 \mathrm{~min}$. A portion of fluid whey was removed for bleaching. Two different bleaching treatments were applied: hydrogen peroxide (HP) and lactoperoxidase. For HP chemical bleaching, $250 \mathrm{mg} / \mathrm{kg}$ of HP was added to liquid whey and allowed to react for $1 \mathrm{~h}$ at $50^{\circ} \mathrm{C}$ with gentle agitation. The concentration of HP was selected because it represents the midrange of the legally allowed amount of HP for traditional chemical bleaching of whey and also represents a concentration that is generally applied by industry (Kang et al., 2010; Listiyani et al., 2011). Catalase (20 mg/kg, FoodPro CAT, Danisco, New Century, NJ) was added at a rate of $20 \mathrm{mg} / \mathrm{kg}$ to remove excess HP and stop the bleaching process. For lactoperoxidase, $20 \mathrm{mg} / \mathrm{kg}$ of $\mathrm{HP}$ was added to fluid whey to activate the enzymatic system and allowed to bleach for $1 \mathrm{~h}$ at $50^{\circ} \mathrm{C}$ with gentle agitation. Catalase was added to remove any excess HP and stop the enzymatic bleaching process. 


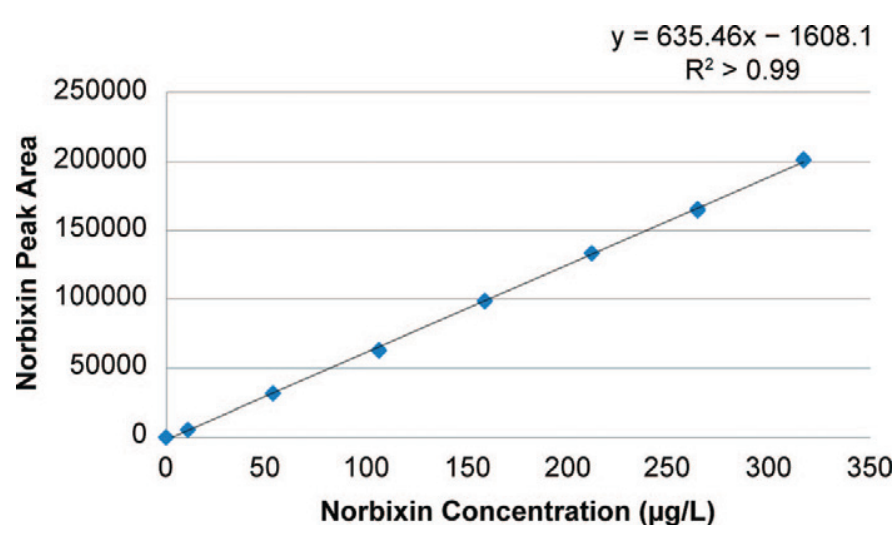

Figure 1. Example calibration curve for norbixin. Color version available in the online PDF.

The remainder of the fluid whey (unbleached) was transferred into a 102-L stainless vat (Fermenator, Blichmann Engineering, Lafayette, IN) equipped with a coil heater $(1 / 2$ " outer diameter, PAC Stainless Ltd., Seattle, WA) and cooled to $50^{\circ} \mathrm{C}$ before ultrafiltration and diafiltration commenced, as described by Campbell et al. (2012). This process continued until the retentate reached $80 \%$ protein (wt/vol) content confirmed by a Sprint rapid protein analyzer (CEM, Matthews, NC). The retentate was then collected and spray dried (model Lab 1, Anhydro Inc., Soeberg, Denmark).

To extract norbixin from milk, $1 \mathrm{~g}$ of colored cheese milk ( $15 \mathrm{~mL}$ of annatto $/ 454 \mathrm{~kg}$ of milk) was added to into a $25-\mathrm{mL}$ volumetric flask and filled to volume with a dilution solution $[80 \%$ acetonitrile and $20 \%$ water with $0.1 \%$ (wt/vol) formic acid; EMD Chemicals, VWR International, West Chester, PA]. A magnetic stirrer was added and the solution was allowed to mix in the dark for $10 \mathrm{~min}$. Two milliliters of the sample were then transferred into an Eppendorf tube (VWR International) and placed in the microcentrifuge at 14,000 $\times$ $g$ for 5 min at room temperature. The clear supernatant was removed and placed into an amber vial for injection (Phenomenex, Torrance, CA).

To extract fluid whey, $2 \mathrm{~g}$ of fluid whey was added to into a $25-\mathrm{mL}$ volumetric flask and filled to volume with dilution solution $[80 \%$ acetonitrile and $20 \%$ water with $0.1 \%$ (wt/vol) formic acid; EMD Chemicals]. The extraction was then carried out as previously described.

To extract fluid whey after bleaching, $2 \mathrm{~g}$ of bleached whey was added to into a $10-\mathrm{mL}$ volumetric flask and filled to volume with dilution solution [ $80 \%$ acetonitrile and $20 \%$ water with $0.1 \%$ (wt/vol) formic acid; EMD Chemicals]. The extraction was then carried out as previously described.

One gram of whey protein concentrate (WPC80) powder was first weighed into a $10-\mathrm{mL}$ volumetric flask. The HPLC-grade water was added to volume (EMD Chemicals). A magnetic stirrer was added and the solution was allowed to mix in the dark for $10 \mathrm{~min}$. Two grams of the whey solution were placed in another 10$\mathrm{mL}$ volumetric flask and filled to volume with dilution solution [ $80 \%$ acetonitrile and $20 \%$ water with $0.1 \%$ (wt/vol) formic acid; EMD Chemicals]. The extraction was then carried out as previously described.

The liquid chromatographic system (Breeze HPLC, Waters, Milford, MA) used consisted of a 1525 binary pump, 2707 automatic injector, 1500 series column heater, and a 2998 photodiode-array detector. Isocratic mobile phase $[70 \%$ acetonitrile and $30 \%$ water with $0.1 \%$ (wt/vol) formic acid; EMD Chemicals] was used at a flow rate of $1 \mathrm{~mL} / \mathrm{min}$ pumped through a binary pump (Waters 1525). Fifty microliters of the sample were injected (Waters 2707 Autosampler) onto the column (Phenomenex Kinetex $2.6 \mu \mathrm{m}$ particle size, 10 $\mathrm{cm}$ in length, $4.6 \mathrm{~mm}$ inner diameter, 100 Á pore size), which was heated to $40^{\circ} \mathrm{C}$. The injector temperature was set to $4^{\circ} \mathrm{C}$. The sample was sent through a photodiode array detector (Waters 2998). The maxima used for calculation was $482 \mathrm{~nm}$. Sample run time was $3 \mathrm{~min}$. An external standard [Double Strength Annatto (3\% Norbixin); Danisco] was used for calibration. Calibration

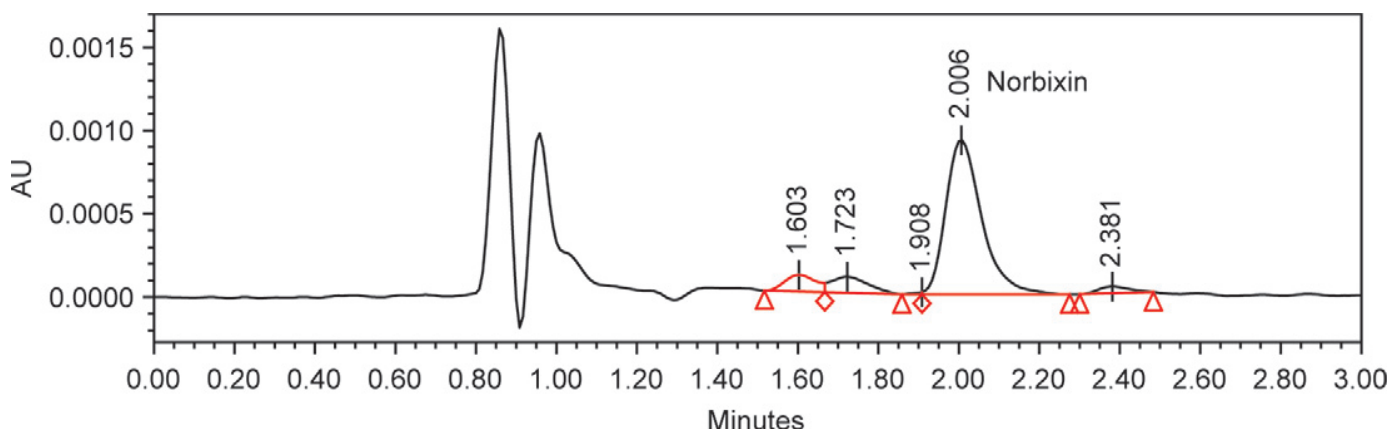

Figure 2. Example chromatogram of norbixin extracted from fluid whey. AU = arbitrary units. Color version available in the online PDF. 


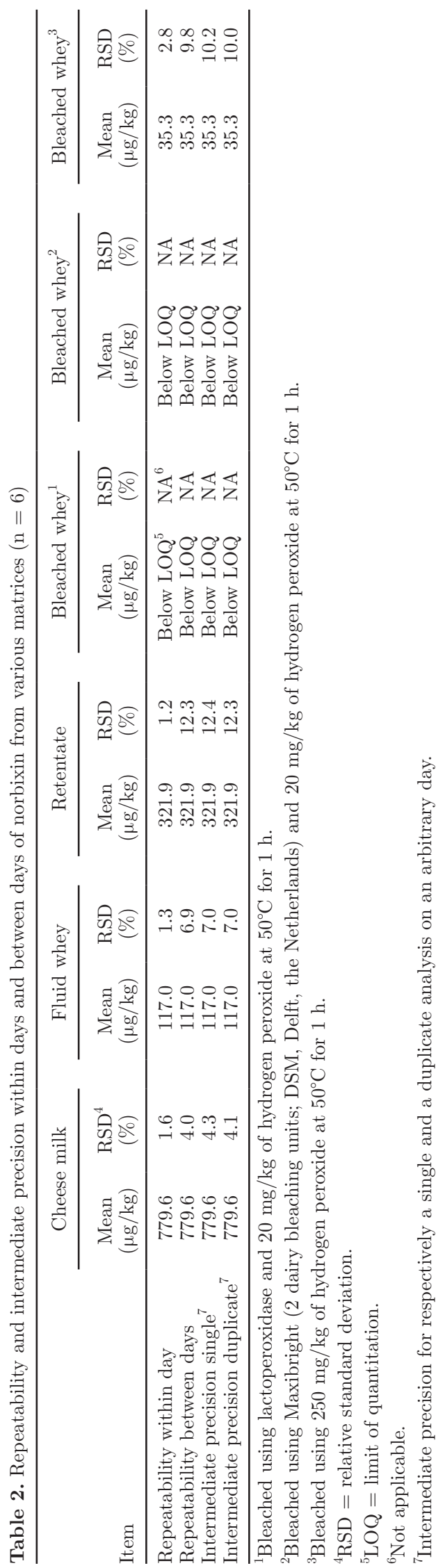

curves were obtained by plotting peak areas of norbixin in solvent [ $70 \%$ acetonitrile and $30 \%$ water with $0.1 \%$ (wt/vol) formic acid; EMD Chemicals] against concentrations of norbixin injected (Figure 1). Norbixin eluted at approximately $2 \mathrm{~min}$ and an example chromatogram can be seen in Figure 2.

Several different approaches to determine limit of detection (LOD) and limit of quantitation (LOQ) exist. In this study, LOD and LOQ were determined based on the norbixin concentration level that generated a signal-to-noise ratio of 3 and 6 , respectively, by adding decreasing concentrations of norbixin to fluid whey samples. The samples were injected 6 times and the relative standard deviation (RSD) was below $10 \%$.

Norbixin was quantitated in dilution solution (blank), fluid whey, and milk matrices over a wide range (0-120 $\mu \mathrm{g} / \mathrm{L})$ of concentrations. Linearity was determined using linear regression.

On 6 different days with 2 different technicians, norbixin was extracted from cheese milk, whey before bleaching, whey after bleaching, and WPC80 retentate and quantified to ensure that the method and results were consistent (Table 2). Extraction and quantitation were carried out as described previously.

Three different levels of norbixin were spiked into either milk or fluid whey (Table 3) and extracted as described previously to determine norbixin recovery during extraction. Recovery was measured in quadruplicate.

At room temperature, sample extracts for cheese milk, whey before and after bleaching, and WPC80 powder were prepared as previously described. Small aliquots were removed at intervals of $5 \mathrm{~min}$ for $30 \mathrm{~min}$ under continuous stirring in the dark at room temperature. Aliquots were then centrifuged at $14,000 \times g$ for $5 \mathrm{~min}$. The supernatant was removed and placed on the HPLC for injection. For stability in the injector, sample extracts for cheese milk, whey before and after bleaching, and WPC80 powder were prepared as described previously. Samples were injected for $24 \mathrm{~h}$ with an interval of $4 \mathrm{~h}$.

Linear regression was calculated using Excel (Microsoft, Redmond, WA) and ANOVA was used to calculate the repeatability and intermediate precision. Other statistical analyses, including RSD, were conducted using Statgraphics (StatPoint Technologies Inc., Warrenton, VA).

The LOD of norbixin in fluid whey was $2.7 \mu \mathrm{g} / \mathrm{kg}$ and the LOQ of norbixin in fluid whey was $3.5 \mu \mathrm{g} /$ $\mathrm{kg}$. Determination of LOD and LOQ were conducted in fluid whey, as matrix will affect the clarity of the chromatogram slightly. The LOD and LOQ of norbixin determined in dilution solution were 2.0 and $3.0 \mu \mathrm{g} / \mathrm{kg}$, respectively, and were lower compared with the LOD 
Table 3. Recovery of norbixin from spiked samples in milk $(\mathrm{n}=4)$ and whey $(\mathrm{n}=4)$

\begin{tabular}{lccccccc}
\hline & \multicolumn{3}{c}{ Level of norbixin in milk } & & \multicolumn{3}{c}{ Level of norbixin in whey } \\
\cline { 2 - 3 } \cline { 7 - 8 } Item (\%) & $78.2 \mu \mathrm{g} / \mathrm{L}$ & $780 \mu \mathrm{g} / \mathrm{L}$ & $2.35 \mathrm{mg} / \mathrm{L}$ & & $9.39 \mu \mathrm{g} / \mathrm{L}$ & $56.3 \mu \mathrm{g} / \mathrm{L}$ & $312.9 \mu \mathrm{g} / \mathrm{L}$ \\
\hline Recovery & $105 \pm 4.1$ & $99 \pm 0.6$ & $96 \pm 10$ & & $102 \pm 3.0$ & $97 \pm 7.0$ & $90 \pm 5.7$ \\
\hline
\end{tabular}

and LOQ determined in matrix $(P<0.05)$. The LOD and LOQ reported in this study were lower than current methods by about 50 fold. A previous norbixin quantification method using HPLC (Scotter et al., 2002) reported an LOD in analyte of $10 \mu \mathrm{g} / \mathrm{kgbut}$, depending on the food commodity analyzed, the LOD was about $100 \mu \mathrm{g} / \mathrm{kg}$. The LOQ calculated from an analyte peak was $100 \mu \mathrm{g} / \mathrm{kg}$ (Scotter et al., 2002). Another published method determining annatto via HPLC in high-fat dairy products, such as cheese and butter, reported an LOQ of $100 \mu \mathrm{g} / \mathrm{kg}$ to $1 \mathrm{mg} / \mathrm{kg}$ depending on the dairy product (Lancaster and Lawrence, 1995).

Norbixin was linear in both the dilution solution (blank) and in fluid whey and milk matrices over a wide range (0-120 $\mu \mathrm{g} / \mathrm{L}$; Figure 3$)$. Linearity was determined using linear regression and $\mathrm{R}^{2}$ values were $>0.99$, indicating that norbixin can be extracted over a range of values.

The repeatability and precision of the method was determined by between day and within day analysis expressed by the RSD (Table 2). The experiment was conducted over $6 \mathrm{~d}$ with 1 set of samples (cheese milk, fluid whey, retentate, and bleached whey) evaluated each day for a total of 6 replications. The method precision was RSD $<13 \%$ for norbixin in all matrices. The repeatability within day $(\mathrm{RSD}<3 \%)$ and between days (RSD $<13 \%)$ was acceptable in all matrices. Previous studies determining norbixin in various matrices reported standard deviations of $1 \%$ (corn snack products; de Oliveira Rios and Mercadante, 2004), $6 \%$ (processed foods; Breithaupt, 2004), and 13\% (meat; Noppe et al., 2009).

Recovery of norbixin from spiked milk and whey was $>90 \%$ over a range of $9.39 \mu \mathrm{g} / \mathrm{L}$ to $2.35 \mathrm{mg} / \mathrm{L}$ (Table 3 ). Recovery percentage for norbixin from both spiked milk and whey were similar and well within those previously reported. Previous studies found a wide range of norbixin recoveries depending on the method and matrix used. Noppe et al. (2009) was able to recover between 99 and $102 \%$ of norbixin in meat tissue, whereas de Oliveira Rios and Mercadante (2004) reported 97\% recovery of annatto in extruded corn snack products. In dairy products, recovery rates of 80 to 100 (Bareth et al., 2002), 93.2 (Lancaster and Lawrence, 1995), and 75 to $96 \%$ (Scotter et al., 2002) have been reported. It is important to note that these methods did not measure

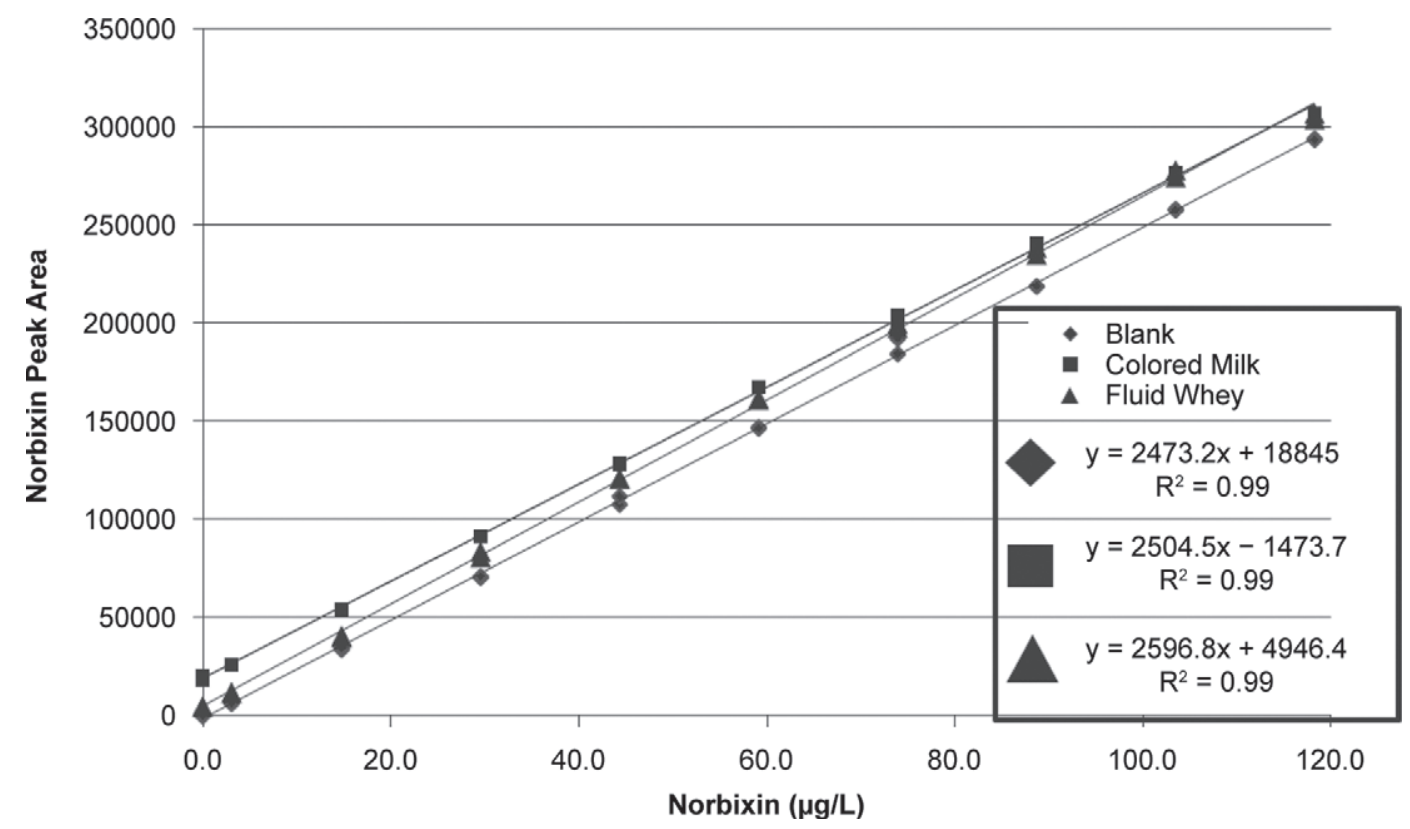

Figure 3. Linearity of norbixin in blank, colored milk, and fluid whey from 0 to $120 \mu \mathrm{g} / \mathrm{L}$. 
norbixin in milk or whey, but rather in other dairy products such as yogurt, cheese, custard, ice cream, and butter. In milk, the quantification of $\beta$-carotene, a carotenoid similar to norbixin, has been widely studied. Recovery of $\beta$-carotene from milk has been reported to be anywhere from 70 (Chauveau-Duriot et al., 2010) to 92.6\% (Liu et al., 1998).

At room temperature, milk, whey, and powder extracts were stable over $30 \mathrm{~min}(P>0.05$; results not shown). The stability of milk, whey, and powder extracts were also tested over $24 \mathrm{~h}$ in the sample injector. The extracts remained stable over $24 \mathrm{~h}$, further proving the robustness of the method $(P>0.05$; results not shown).

The developed method provides a fast and inexpensive norbixin extraction and quantitation technique with better sensitivity than current methods. In addition, solvent waste is greatly reduced compared with current methods and only approved solvents are used, so the method can be used in countries with stricter chemical regulations.

\section{ACKNOWLEDGMENTS}

Funding provided in part by DSM Food Specialties (Delft, the Netherlands) and the Dairy Research Institute (Rosemont, IL). The use of tradenames does not imply endorsement or lack of endorsement by those not mentioned.

\section{REFERENCES}

Bareth, A., W. Strohmar, and E. Kitzelmann. 2002. HPLC and spectrophotometric determination of annatto in cheese. Eur. Food Res. Technol. 215:359-364.
Breithaupt, D. 2004. Simultaneous HPLC determination of carotenoids used as food coloring additives: Applicability of accelerated solvent extraction. Food Chem. 86:449-456.

Campbell, R. E., E. J. Kang, E. Bastian, and M. A. Drake. 2012. The use of lactoperoxidase for the bleaching of fluid whey. J. Dairy Sci. 95:2882-2890.

Campbell, R. E., R. E. Miracle, and M. A. Drake. 2011. The impact of starter culture and annatto on the flavor and functionality of whey protein concentrate. J. Dairy Sci. 94:1185-1193.

Chauveau-Duriot, B., M. Doreau, P. Noziere, and B. Graulet. 2010. Simultaneous quantification of carotenoids, retinol, and tocopherols in forages, bovine plasma, and milk: Validation of a novel UPLC method. Anal. Bioanal. Chem. 397:777-790.

Croissant, A. E., E. J. Kang, R. E. Campbell, E. Bastian, and M. A Drake. 2009. The effect of bleaching agent on the flavor of liquid whey and whey protein concentrate. J. Dairy Sci. 92:5917-5927.

de Oliveira Rios, A., and A. Z. Mercadante. 2004. Novel method for the determination of added annatto color in extruded corn snack products. Food Addit. Contam. 21:125-133.

Kang, E. J., R. E. Campbell, E. Bastian, and M. A. Drake. 2010. Annatto and bleaching in dairy foods. J. Dairy Sci. 93:3891-3901.

Kang, E. J., T. J. Smith, and M. A. Drake. 2012. Alternative bleaching methods for Cheddar cheese whey. J. Food Sci. 77:C818-C823.

Kovary, K., T. A. Louvain, M. C. Costa e Silva, F. Albano, B. M. B. Pires, G. A. T. Liaranja, C. L. S. Lage, and I. Felzenszwalb. 2001. Biochemical behavior of norbixin during invitro DNA damage induced by reactive oxygen species. Br. J. Nutr. 85:431-440.

Lancaster, F. E., and J. F. Lawrence. 1995. High-performance liquid chromatographic separation of carminic acid, a- and b-bixin, and a- and b-norbixin, and the determination of carminic acid in foods. J. Chromatogr. 732:394-398.

Listiyani, M. A. D., R. E. Campbell, R. E. Miracle, L. O. Dean, and M. A. Drake. 2011. Influence of bleaching on flavor of $34 \%$ whey protein concentrate and residual benzoic acid concentration in dried whey proteins. J. Dairy Sci. 94:4347-4359.

Liu, Y., M. J. Xu, and I. M. Canfield. 1998. Enzymatic hydrolysis, extraction, and quantitation of retinol and major carotenoids in mature human milk. Nutritional Biochem. 9:178-183.

Noppe, H., A. Mertinez, K. Verheyden, J. Van Loco, R. Companyo Beltran, and H. F. de Brabander. 2009. Determination of bixin and norbixin in meat using liquid chromatography and photodiode array detection. Food Addit. Contam. A Chem. Anal. Control Expo. Risk Assess. 26:17-24

Scotter, M. J., L. Castle, C. A. Honeybone, and C. Nelson. 2002. Method development and analysis of retail foods for annatto food colouring material. Food Addit. Contam. 19:205-222. 